\title{
Tsafon
}

Revue d'études juives du Nord

$74 \mid 2017$

La Déclaration Balfour, vers l'État d'Israël ?

\section{Danièle Iancu-Agou, Régine-Catherine et Bonet de Lattes}

Danielle Delmaire

\section{(2) OpenEdition}

1 Journals

Édition électronique

URL : https://journals.openedition.org/tsafon/431

DOI : $10.4000 /$ tsafon.431

ISSN : 2609-6420

Éditeur

Association Jean-Marie Delmaire

Édition imprimée

Date de publication : 1 décembre 2017

Pagination : 165-167

ISSN : 1149-6630

\section{Référence électronique}

Danielle Delmaire, « Danièle lancu-Agou, Régine-Catherine et Bonet de Lattes », Tsafon [En ligne], 74 |

2017, mis en ligne le 31 mai 2018, consulté le 24 juin 2021. URL : http://journals.openedition.org/ tsafon/431; DOI : https://doi.org/10.4000/tsafon.431

Ce document a été généré automatiquement le 24 juin 2021.

Tsafon. Revues d'études juives du Nord 


\title{
Danièle Iancu-Agou, Régine-Catherine et Bonet de Lattes
}

\author{
Danielle Delmaire
}

\section{RÉFÉRENCE}

Danièle Iancu-Agou, Régine-Catherine et Bonet de Lattes, Biographie croisée 1460-1530, Draguignan/Aix-en-Provence/Rome, Paris, éd. du Cerf, juin 2017, 348 p., $24 €$.

Danièle Iancu-Agou est connue pour ses travaux sur les communautés juives médiévales en Provence et en Languedoc. Voilà environ quarante années qu'elle travaille le sujet. Cela lui donna l'occasion de rencontrer les noms de Régine Abram et Bonnet de Lattes. Mais cette fois, écrit-elle dans le préambule: «Je reviens avec gratitude vers un couple singulier d'il y a 500 ans qui m'a offert et m'offre toujours - les plus belles joies d'archives dont un chercheur peut rêver. En retour, il me faut leur redonner vie et tenter d'écrire leur biographie croisée ». Danièle Iancu-Agou exprime là des sentiments qu'il arrive au fouilleur d'archives d'éprouver lorsqu'il parvient à suivre les étapes d'un parcours de vie. Le récit intimiste n'exclut nullement la distanciation scientifique mais il faut reconnaître que des personnages découverts en dépouillant des dossiers poussiéreux attirent notre sympathie ou notre antipathie ${ }^{1}$.

2 Malgré ou à cause de sa sympathie envers ses amis d'il y a 500 ans, Danièle Iancu-Agou prend soin de contextualiser le déroulement de leur vie dans la Provence et l'Italie des $\mathrm{XV}^{\mathrm{e}}$ et $\mathrm{XVI}^{\mathrm{e}}$ siècles et ne s'écarte pas des rigueurs de la méthodologie scientifique lorsque les archives imposent le doute. Il faut ajouter encore le souci pédagogique de résumer ou reconstituer un parcours après un long développement qui expose les procédés de la recherche. Car l'auteure mène une enquête minutieuse pour démêler un écheveau bien enchevêtré afin de faire revivre les vivants à travers les testaments qui renferment les volontés des morts.

3 Régine Abram et Bonnet de Lattes appartiennent tous deux à des familles juives, aisées et lettrées de Provence, pour lesquelles la médecine et le commerce sont sources de 
revenus confortables. Dans le contexte d'une société provençale très ouverte aux juifs sous le règne du bon roi René, ces familles coulent des jours paisibles d'autant que le roi s'oppose aux conversions forcées même s'il est convaincu que les juifs sont bien dans l'erreur. Cette situation n'empêche tout de même pas des convertisseurs zélés d'agir par des rapts d'enfants rappelant l'affaire Mortara qui s'est déroulée 400 ans plus tard. Bien que récemment mariée à Bonnet qui refuse d'apostasier, la jeune Régine Abram tombe dans les rets d'un Gillet Gilibert qui ne s'encombre pas de délicatesse pour convertir malgré la position royale. Elle devient chrétienne et le couple se sépare. Cette mésaventure pour Bonnet illustre la prévalence du droit chrétien sur le droit juif sans que celui-ci disparaisse. Régine devenue Catherine par son baptême peut épouser Gillet dans la religion catholique puisque son mariage selon le rite juif avec Bonnet n'est pas reconnu par l'Église tandis que, selon les lois juives, Bonnet est tenu de rembourser la dot qu'il a reçue de la famille de Régine-Catherine. Il est, finalement, victime de deux législations qui se côtoient et s'entremêlent : chrétienne et juive.

Devenue veuve, Catherine se remarie ( $3^{\mathrm{e}}$ mariage mais $2^{\mathrm{e}}$ mariage catholique) avec un personnage dont elle se sépare rapidement, de fait mais non pas légalement puisque le mariage catholique ne peut être dissout. Puis elle semble en finir avec ses unions, mais il n'en est rien. Au détour d'un testament, Danièle Iancu-Agou découvre qu'en fait elle a une aventure avec un personnage, catholique, et dont elle a deux enfants. Elle finit par l'épouser après le décès de son $3^{\mathrm{e}}$ époux. L'historienne restitue une vie bien mouvementée, digne d'un roman, menée par une femme de tête qui sait défendre ses intérêts, vivre selon ses désirs tout en bravant des interdits de sa nouvelle religion. En dissimulant les épisodes immoraux, selon le christianisme, elle parvient à se placer favorablement à la cour du roi et sa conversion lui évite les violences et expulsions imposées aux juifs après la mort du bon roi.

Dans le sillage de Régine-Catherine, Danièle Iancu-Agou fait pénétrer ses lecteurs dans la communauté des néophytes. Ils sont nombreux à rester entre eux par alliances matrimoniales ou activités professionnelles. L'auteure va jusqu'à soupçonner la pratique d'un crypto-judaïsme.

$6 \quad$ Et pendant que Catherine convole en plusieurs noces, que devient Bonnet ? Après sa séparation, il s'acquitte non sans difficultés de sa dette maritale. Il n'est absolument pas sensible aux appels des sirènes de la conversion et reste fidèle à la religion de ses pères. Il pratique toujours la médecine dans sa Provence natale jusqu'à ce que s'abattent les agressions antijuives sur les communautés, à la fin $\mathrm{du}_{\mathrm{xv}} \mathrm{e}$ siècle. De nouveau, dangereusement menacés de nombreux juifs se convertissent contraints et forcés. Mais ce n'est pas le cas de Bonnet qui, comme d'autres coreligionnaires, préfère l'exil en Italie. Après plusieurs étapes, il s'établit à Rome où il parvient à pratiquer son art et même à devenir le médecin du pape ! Finalement il jouit de la reconnaissance publique tout en demeurant juif. Régine-Catherine bénéficie d'une même reconnaissance mais en apostasiant son judaïsme et ce qui ne l'empêche pas de mener une vie agitée, parfois éloignée de la morale catholique. Le récit parallèle de ces deux vies est porteur de nombreux indices sur la vie dans les communautés juives provençales médiévales, les cercles des néophytes qui ne s'intègrent pas toujours dans la société environnante, enfin sur les familles juives fidèles à leur religion malgré les persécutions et soumises à d'incessants exils.

Quelle belle histoire romanesque, nullement un roman historique, que l'historienne des communautés juives de Provence au Moyen Âge nous donne à lire ! 


\section{NOTES}

1. Lors de mes travaux sur les Juifs durant la Révolution en France septentrionale, il m'est arrivé également de ressentir cette même sympathie envers une femme qui, pendant plus d'un mois, révèle, durant une enquête de police, les méfaits de sa bande. 